Marquette University

e-Publications@Marquette

College of Nursing Faculty Research and

Publications

Nursing, College of

9-1-2014

\title{
Comparison of Abstinence and Coital Frequency Between 2 Natural Methods of Family Planning
}

Richard J. Fehring

Marquette University, richard.fehring@marquette.edu

Mary Schneider

Marquette University, mary.schneider@marquette.edu

Accepted version. Journal of Midwifery \& Women's Health, Vol. 59, No. 5 (September/October 2014): 528-532. DOI. (C) 2014 John Wiley \& Sons. Used with permission. 


\title{
Comparison of Abstinence and Coital Frequency Between 2 Natural Methods of Family Planning
}

\author{
Richard J. Fehring \\ College of Nursing, Marquette University \\ Milwaukee, WI \\ Mary Schneider \\ College of Nursing, Marquette University \\ Milwaukee, WI
}

\section{Abstract}

Introduction: The length of periodic abstinence, due to overestimation of the fertile phase of the menstrual cycle, is often a cause for dissatisfaction, discontinuation, and user error with natural family planning (NFP) methods. The objective of this research was to compare the length of required abstinence (ie, estimated fertility) and coital frequency between 2 NFP methods.

Methods: This was an analysis of data from a 12-month prospective comparison study in which participants were randomized into either an electronic hormonal fertility monitor (EHFM) group or a cervical mucus monitoring (CMM) group-both of which included a fertility algorithm as a

Journal of Midwifery \& Women's Health, Vol 59, No. 5 (September/October 2014): pg. 528-532. DOI. This article is (C) Wiley and permission has been granted for this version to appear in e-Publications@Marquette. Wiley does not grant permission for this article to be further copied/distributed or hosted elsewhere without the express permission from Wiley. 
double check for the beginning and end of the estimated fertile window. The number of days of estimated fertility and coitus was extracted from each menstrual cycle of data, and $t$ tests were used to compare the means of these 2 variables between the 2 NFP methods.

Results: The study involved 197 women (mean [SD] age 29.7 [5.4]) who used the EHFM to estimate the fertile window and 160 women (mean [SD] age 30.4 [5.3]) who used CMM to estimate the fertile window. They produced 1,669 menstrual cycles of data. After 12 months of use, the EHFM group had statistically fewer days of estimated fertility than the CMM group (mean [SD] days, 13.25 [2.79] vs 13.68 [2.99], respectively; $t=2.07 ; P=.039$ ) and significantly more coitus (mean [SD] coital acts, 4.22 [3.16] vs 4.05 [2.88], respectively; $t=1.17 ; P=.026)$.

Discussion: The use of the EHFM seems to provide more objectivity and confidence in self-estimating the fertile window and using nonfertile days for intercourse when avoiding pregnancy.

\section{Introduction}

Although fertility awareness-based methods of natural family planning (NFP) are accepted by many cultures and religions and are free of side effects, they are used by only $0.1 \%$ of women in the United States who are of reproductive age.[1,2] Periodic abstinence requirements and anxiety over unintended pregnancy could explain some lack of use and acceptance of NFP methods.[3-6] Current NFP methods overestimate the actual 6-day fertile window by 6 to 11 days, with most methods requiring 12 to 14 days or more of abstinence to avoid pregnancy.[7-9] Dissatisfaction with length of abstinence often leads to discontinuation, user error (ie, intercourse on estimated days of fertility), and unintended pregnancy.[10,11]

In an effort to develop a modern method of NFP based on the latest hormonal monitoring technology, we developed and tested a natural method of family planning that involved both electronic hormonal fertility monitoring (EHFM) and cervical mucus monitoring (CMM) to estimate the fertile time of the menstrual cycle.[12-15] However, although this method was relatively effective, it was rather complex to teach and use. We then developed a simplified NFP method based on either CMM or EHFM (or both) and a simple fertility algorithm as a double check for the beginning and end of the fertile phase. [14] Table 1 describes an updated algorithm, first published in 2005.[12] As indicated in Table 1 , the algorithm changes after 6 cycles of use based on the earliest and latest peak fertility rating (from the monitor or mucus or both) from the previous 6 cycles. 
NOT THE PUBLISHED VERSION; this is the author's final, peer-reviewed manuscript. The published version may be accessed by following the link in the citation at the bottom of the page.

Table 1. Marquette Model Natural Family Planning Algorithm for Avoiding Pregnancy

Abbreviations: CMM, cervical mucus monitoring; EHFM, electronic hormonal fertility monitor; NFP, natural family planning.

\section{To Avoid Pregnancy}

In order to avoid pregnancy one should not have intercourse or genital contact during the fertile window-ie, from the first day of fertility through the last day of fertility. The length and time of the fertile window will vary from cycle to cycle. Couples who are using the electronic hormonal fertility monitor (EHFM) or cervical mucus monitoring (CMM) as an aid to avoiding pregnancy should refrain from intercourse on all high and peak observation days and can employ the following algorithm for determining the fertile window.

\section{To Determine the Beginning of the Fertile Window}

1. Your fertility begins on day 6 of the first 6 menstrual cycles.

2. After 6 cycles, your fertility begins on the earliest day of a peak observation (mucus or monitor) during the last 6 cycles minus 6 days or the first "high" observation (mucus or monitor)-whichever comes first.

\section{To Determine End of the Fertility Window}

3. Your fertility ends on the last peak day plus 3 full days.

4. After 6 cycles, your fertility ends on the last peak day plus 3 full days, or the last peak day of the last 6 cycles plus 3 full days-whichever comes first.

This algorithm is to be used only for those women who have cycles between 21 and 42 days in length. If there are 2 or more cycles that fall out of that range, or the menstrual cycles vary by more than 10 days, see your professional nurse NFP teacher for advice.

Please see your professional nurse NFP teacher for separate protocols for discontinuing hormonal contraception and if you are currently postpartum, postpartum breastfeeding, or perimenopausal.

Subsequently, we constructed an online system to teach couples how to use this new NFP method, which included an online charting system that automatically calculated the fertile window based on the new algorithm.[16] A prospective randomized comparison of EHFM with $\mathrm{CMM}[16,17]$ showed that EHFM plus fertility algorithm was more effective in helping couples avoid pregnancy, with 8 unintended pregnancies per 100 users over 12 months of use compared with 18.5 pregnancies with CMM plus fertility algorithm.[17] Since we also collected menstrual cycle charting data on the participants in this study, we were interested in determining the length of the estimated fertile windows, as calculated by these 2 methods of NFP (ie, the duration of required abstinence) and the frequency of coitus during the infertile phases.

The specific purposes of this study were: 1) to compare the length of the estimated fertile window, as determined by EHFM (plus 
algorithm) with the estimated fertile window by use of CMM (plus algorithm), and 2) to compare coital frequency between the 2 NFP methods. We predicted that over time (ie, over 12 cycles of use) the EHFM plus algorithm would lead to a shorter estimated fertile window compared with the CMM method and greater coital frequency.

- Excessive required abstinence with use of natural methods of family planning often leads to dissatisfaction and unintended pregnancies.

- Two new methods of natural family planning have been developed that incorporate either electronic hormonal fertility monitoring (EHFM) or a simplified form of cervical mucus monitoring (CMM) with a simple fertility algorithm to determine the beginning and end of the fertile phase of the menstrual cycle.

- The EHFM method had fewer days of required abstinence than the CMM method.

\section{Methods}

This study was a secondary analysis of data from an existing data set produced through a 12-month prospective randomized clinical comparison study of the efficacy of the EHFM plus fertility algorithm method of NFP with CMM plus fertility algorithm. The EHFM used for this study was the Clearblue Easy Fertility Monitor (Swiss Precision Diagnostics GmbH; Geneva, Switzerland). This study and the current study received human participants approval through the Marquette University Office of Research Compliance, Milwaukee, WI. The study was registered at ClinicalTrials.gov with the identification number NCT00843336.

The inclusion criteria for female partners of the couple participants were aged between 18 and 42 years; stated menstrual cycle range of 21 to 42 days; no history of hormonal contraceptives for the past 3 months; and if recently breastfeeding, at least 3 cycles past weaning. We recruited couple participants from April 2008 through December 2010, via an online search engine advertisement, e-mail lists, and by word-of-mouth through fertility blogs and social networking sites. 
All EHFM participants used the Clearblue Easy Fertility Monitor, which detects rising levels of urinary estrone-3-gluconuride (E3G) and is $98.8 \%$ accurate in detecting the surge in urinary luteinizing hormone $(\mathrm{LH}) \cdot[18,19]$ The handheld fertility monitor is initiated when a user pushes a button on the monitor labeled $M$ on the first day of her menses. The monitor requests either 10 or 20 daily urine tests per cycle. The monitor costs approximately $\$ 200$ and test strips cost from $\$ 17$ to $\$ 25$ per menstrual cycle. When the monitor requests a test, the user exposes the strip to her urine stream for 3 seconds and places it in the monitor. Within 5 minutes, the monitor will show a fertility status of low, high, or peak. The high reading indicates a significant rise in E3G, and the peak reading indicates a threshold level of $\mathrm{LH}$.

The CMM participants were asked to observe their cervical mucus on a daily basis and to chart the most fertile mucus sign at the end of the day. Their cervical mucus was rated as low, high, and peak based on visual descriptions and pictures of the 3 levels that were provided online to the CMM users (see Figure 1).

All participants were asked to view an online 10-minute video on how to observe their assigned method of estimating fertility and how to chart their findings. Participants in both groups were asked to record their daily fertility status (low, high, or peak), all coital acts, and their menstrual bleeding days using the Marquette University Institute for NFP online electronic charting system (http://nfp.marquette.edu). The charting system automatically indicates the fertile phase based on the algorithm (Figures $\underline{1}-\underline{2}$; fertile phase in tinted area). Participants were also instructed to avoid intercourse and genital contact during the fertile window (ie, from the first day of fertility through the last day of fertility) and to refrain from intercourse on all high and peak days. The online NFP Web site also includes written quick instructions, a downloadable user manual, downloadable menstrual cycle charts, and instructions for special reproductive circumstances such as postpartum breastfeeding. Participants who register on the password-protected Web site also have access to the online charting system and user forums, as well as private message consultation from professional nurses with expertise in NFP methods. 


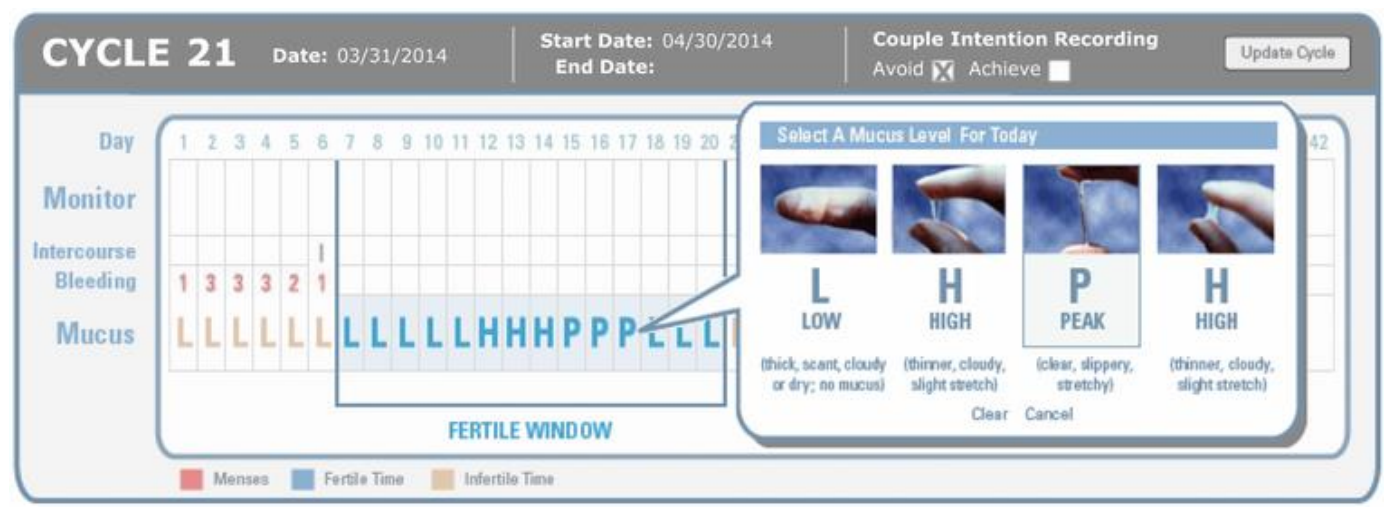

Figure 1. Example of Online Chart System to Estimate the Fertile Window of the Menstrual Cycle with Self-Rating of Cervical Mucus

Source: http://nfp.marquette.edu/charting_monitoring_intro.php

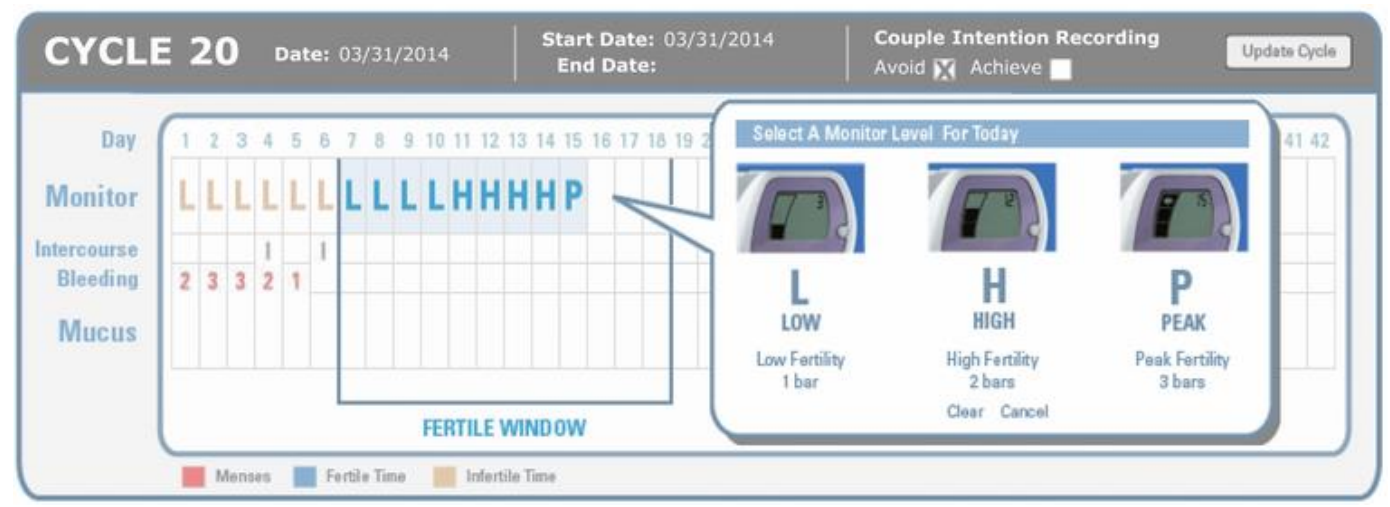

Figure 2. Example of Online Chart System to Estimate the Fertile Window of the Menstrual Cycle with a Handheld Electronic Hormonal Fertility Monitor Source: http://nfp.marquette.edu/charting monitoring intro.php

Professional nurse, graduate-student research assistants (who were seasoned NFP teachers) downloaded the following into an electronic dataset: menstrual cycle parameters, length of estimated fertile window, and frequency of intercourse for all menstrual cycles charted. Data were analyzed with the IBM Statistical Package for the Social Sciences (IBM SPSS Version 19, Armonk, New York) software systems. Differences in mean days of fertility and frequency of intercourse between the EHFM and CMM groups were determined by use of the student $t$ test, with statistical significance set at a $P$ value below 05 . 
NOT THE PUBLISHED VERSION; this is the author's final, peer-reviewed manuscript. The published version may be accessed by following the link in the citation at the bottom of the page.

\section{Results}

\section{Participants}

We recruited 667 couple participants from April 2008 through December 2008. Of these, 357 (53.5\%) who registered contributed online charting. Reasons for dropping out of the study and the participant diagram tree can be found in our original efficacy study.[17] Mean age, number of years married, number of living children, basal metabolic index, and age of husband/partner of the 197 participants in the EHFM group and the 160 participants in the CMM group are shown in Table 2 . There were no significant statistical differences in the demographics between the 2 groups of participants. For both groups, the greatest percentages of participants were white and Catholic. They produced a total of 1,663 menstrual cycles of data, 1,027 for the EHFM group and 636 for the CMM group.

Table 2. Comparison of Participant Characteristics Between the Monitor and Mucus Group

$\begin{array}{ccc}\text { Participant } & \text { Monitor } & \text { Mucus } \\ \text { Characteristics } & (\mathrm{n}=197) & (\mathrm{n}=160)\end{array}$

Abbreviations: BMI, basal metabolic index; SD, standard deviation.

$\begin{array}{lll}\text { Age, female, mean (SD), y } & 29.7(5.4) & 30.4(5.3) \\ \text { Age, male, mean (SD), y } & 31.5(6.1) & 32.5(6.2) \\ \text { Married, mean (SD), y } & 5.8(5.0) & 6.3(5.1) \\ \text { Living children, mean (SD) } & 1.8(1.9) & 2.1(1.9) \\ \text { BMI female, mean (SD) } & 24.7(4.7) & 25.3(5.9) \\ \text { Ethnicity of female partner, } \mathbf{n}(\%) & & \\ \text { White } & 152(77) & 134(84) \\ \text { Hispanic } & 13(7) & 8(5) \\ \text { Asian } & 3(2) & 1(1) \\ \text { Native American } & 3(2) & 1(1) \\ \text { Other } & 24(12) & 14(9) \\ \text { Religion of female partner, } \mathbf{n}(\%) & & \\ \text { Catholic } & 150(76) & 130(81) \\ \text { Protestant } & 36(18) & 23(14) \\ \text { Other } & 11(6) & 7(4)\end{array}$




\section{Length of Estimated Fertile Window}

There was no difference in mean number of days of estimated abstinence (ie, estimated fertile phase) between the EHFM or CMM groups (mean [SD] days 14.34 [4.04] vs mean [SD] days 14.19 [3.86], respectively; $t=.732, P=.464$ ) when all cycles were included in the analysis. However, after the first 6 cycles and the adjusted algorithm from data provided by the previous 6 cycles, the EHFM had significantly fewer days of abstinence, that is, a shorter estimated fertile window with a mean (SD) length of 13.25 (2.79) days versus 13.68 (2.99) days for the CMM group $(t=2.07 ; P=.039)$.

\section{Frequency of Coitus}

There was significantly more coitus in the EHFM group than in the CMM group, with a mean (SD) number of coital acts per menstrual cycle of 4.22 (3.16) versus $4.05(2.88)(t=1.17 ; P=.026)$ over 12 months of use.

\section{Discussion}

This is the first study to compare length of abstinence and coital frequency between 2 online modern methods of NFP (ie, the EHFM method and the CMM method). Overall we found that there was no difference in the number of estimated fertile days and the required time for abstinence from acts of intercourse between the 2 online methods of NFP when all menstrual cycles charted are included in the analysis over 12 cycles of use. It was expected that there would be no difference in the estimated days of fertility during the first 6 cycles of use; both the EHFM group and the CMM group used the same algorithm of starting the estimated fertile phase on day 6 . In addition, women in the CMM group were asked to ignore the low-level rated mucus and to only rate the stretchy mucus as high and peak. This method of rating mucus significantly reduced estimated days of fertility using cervical mucus as a marker of fertility. This is evident based on the comparison of mucus versus monitor in an earlier study and the earlier method of NFP that included both CMM and EHFM.[9] However, as hypothesized, there were fewer days of abstinence (ie, a shorter estimated fertile phase) with the EHFM after the fertility 
algorithm adjusted with 6 cycles of use. The fewer days of abstinence were most likely due to the greater precision of the EHFM and identifying the LH surge as the marker for ovulation, as well as to the overestimation of fertile days with mucus monitoring.[9, 20-22]

The adjusted 6-cycle average of 13 to 14 days of required abstinence (for both monitor and mucus) is less than reports that estimate an average of 17 days of required abstinence for other cervical mucus-only methods.[를 Use of the monitor provides accuracy and objectivity to estimating the fertile phase; for CMM users, rating cervical mucus as low, high, and peak results in fewer days that are labeled as fertile, and eliminates mucus that is often not related to estrogen stimulation and fertility. On the other hand, the 13 to 14 days of required abstinence estimated in this study is more than the 12 days of required abstinence estimated by a fixed-day calendar method. Nonetheless, it is comparable to combination NFP methods that use, for example, mucus and basal body temperature as natural biologic markers of fertility. $[\underline{7,24}]$

As hypothesized, there were significantly more acts of intercourse by couples in the EHFM group. The average of 4 acts of intercourse per menstrual cycle for this study is less than that found with a fixed-day calendar method of family planning and less than that among couples using contraception, which averages around 6 acts per month.[25] One might assume that as couples become confident in the method through use, there would be more acts of coitus. On the contrary, there was less intercourse in the second 6 cycles of use for both methods. However, there were more acts of intercourse with the EHFM method compared with the CMM method. We suspect that the monitor provides more confidence in estimating the fertile window; thus, couples are more confident that they will not have an unintended pregnancy. There is also a strong possibility that all acts of intercourse are not recorded online.

Participants in the study were only eligible if they had menstrual cycles of regular lengths, which limits generalizability. However, this study was more generous than most studies in that our inclusion cycle length was from 21 to 42 days (the cycle length that the EHFM is able to cover efficiently). Including longer cycle lengths most likely would increase the estimated days of fertility. In addition, this study did not 
include women during the first 3 cycles after the cessation of breastfeeding nor did it include postpartum women or women older than 42 years of age. Older women in the perimenopause years will have greater variability in cycle lengths and possibly more days of estimated fertility based on natural indicators of fertility. Finally, this study excluded women who were less than 3 cycles posthormonal birth control; these women often have more mucus days, delays in ovulation, and longer cycles.[26]

Future studies on estimating the days of fertility, and subsequently days of abstinence among women using methods of NFP, must address special groups such as postpartum women (breastfeeding or not), women with long cycle lengths, perimenopausal women, and women who have recently used hormonal contraception. Planned further studies also include adjusting and testing a fertility algorithm that might provide fewer estimated days of abstinence but not lose effectiveness in helping couples avoid pregnancy with natural methods.

\section{Conclusion}

The EHFM plus fertility algorithm provides more objective measures of the fertile window of the menstrual cycle than use of CMM, and as a result, fewer days of abstinence for those couples using these methods of NFP to avoid pregnancy. Fewer days of abstinence was also associated with more frequent intercourse among the EHFM users. The decreased amount of required abstinence and the increased frequency of intercourse might have contributed to the greater satisfaction and ease of use for participants in the EHFM group that was noted in an earlier study on the efficacy of these natural methods of birth control.[17] The expense of using the EHFM and monthly test strips compared to no cost with monitoring cervical mucus changes must be considered when recommending either method for family planning use. Use of the EHFM and/or the CMM with the fertility algorithm as methods of NFP provides an amount of required abstinence in line with or less than other common forms of NFP such as mucus, basal body temperature, or symptom-thermal method. 
NOT THE PUBLISHED VERSION; this is the author's final, peer-reviewed manuscript. The published version may be accessed by following the link in the citation at the bottom of the page.

\section{Conflict Of Interest}

The authors have no conflicts of interest to disclose.

\section{Acknowledgements}

This study was funded by a grant from the Department of Health and Human Services, Public Health Service (Office of Population Affairs) number FPRPA006034-02-01.

We wish to thank Thomas Bouchard, MD, a private practice physician and adjunct faculty in the Department of Family Medicine at the University of Calgary School of Medicine, Alberta, Canada, for his consultation and expertise on this project.

\section{Biographies}

- Richard J. Fehring, PhD, RN, FAAN, is Professor of Nursing at Marquette University College of Nursing and Director of the Marquette University College of Nursing Institute for Natural Family Planning, Milwaukee, Wisconsin.

- Mary Schneider, MSN, APRN, is Certified Family Nurse Practitioner and doctoral student at Marquette University College of Nursing, Milwaukee, Wisconsin.

\section{REFERENCES}

${ }^{1}$ Mosher WD. Use of contraception and use of family planning services in the United Sates: 1982-2002. Adv Data 2004;10:1-36.

2Pallone SR, Bergus JR. Fertility awareness-based methods: Another option for family planning. J Am Board Fam Med. 2009; 22:147-57.

${ }^{3}$ Moreau C, Cleland K, Trussell J. Contraceptive discontinuation attributed to method dissatisfaction in the United States. Contraception. 2007;76(4):267-72.

${ }^{4}$ Fehring R, Hanson L, Stanford J. Nurse-midwives' knowledge and promotion of lactational amenorrhea and other natural family-planning methods for child spacing. J Midwifery Womens Health. 2001;46:68-73.

${ }^{5}$ VandeVusse L, Hanson L, Fehring R., et al. Couples' views of the effects of natural family planning. J Nurs Scholarsh. 2003;35(2):171-176.

${ }^{6}$ Oddens BJ. Women's satisfaction with birth control: A population survey of physical and psychological effects of oral contraceptives, intrauterine devices, condoms, natural family planning, and sterilization among 1466 women. Contraception. 1999;59(5):277-286.

Journal of Midwifery \& Women's Health, Vol 59, No. 5 (September/October 2014): pg. 528-532. DOI. This article is (C Wiley and permission has been granted for this version to appear in e-Publications@Marquette. Wiley does not grant permission for this article to be further copied/distributed or hosted elsewhere without the express permission from Wiley. 
NOT THE PUBLISHED VERSION; this is the author's final, peer-reviewed manuscript. The published version may be accessed by following the link in the citation at the bottom of the page.

${ }^{7}$ World Health Organization. Temporal relationships between indices of the fertile period. Fertil Steril. 1983;39(5): 647-655.

${ }^{8}$ Wilcox, et al., Timing of sexual intercourse in relation to ovulation. $N$ Engl $\mathrm{J}$ Med. 1995;333(23):1517-1521.

${ }^{9}$ Fehring, R, Raviele, K, Schneider, M. A comparison of the fertile phase as determined by the Clearplan Easy Fertility Monitor and self-assessment of cervical mucus. Contraception. 2004;69:9-14.

${ }^{10}$ Leite IC, Gupta N. Assessing regional differences in contraceptive discontinuation, failure and switching n Brazil. Reprod Health. 2007;46.

${ }^{11}$ Moreau C, Cleland K, Trussell J. Contraceptive discontinuation attributed to method dissatisfaction in the United States. Contraception. 2007;76(4):267-272.

${ }^{12}$ Fehring R. New low and high tech calendar methods of family planning. $J$ Midwifery Womens Health. 2005;50:31-37.

${ }^{13}$ Fehring R, Schneider M, Raviele K. Efficacy of hormonal fertility monitoring as a method of natural family planning. J Obst Gynecol Neonat Nurs 2007;36:152-160.

${ }^{14}$ Fehring R, Schneider M, Barron ML. Retrospective efficacy of the Marquette Model of natural family planning. MCN Am J Matern Child Nurs. 2008;33:348-354.

${ }^{15}$ Fehring R, Schneider M, Barron ML, Raviele K. Cohort comparison of two fertility awareness methods of family planning. J Reprod Med. 2009; 54:165-170.

${ }^{16}$ Fehring R, Schneider M, Raviele K. Pilot evaluation of an internet-based natural family planning education and service program. $J$ Obstet Gynecol Neonat Nurs. 2011;40(3):281-291.

${ }^{17}$ Fehring, R., Schneider, M., Raviele, K, Rodriguez, D. Randomized comparison of two Internet-supported fertility awareness based methods of family planning. Contraception. 2013;88(1): 24-30.

${ }^{18}$ May K. Home monitoring with the ClearPlan Easy Fertility Monitor for fertility awareness. J Internat Med Res. 2001;29(suppl 1):14A-20A.

${ }^{19}$ Unipath Diagnostics. Professional Information: ClearPlan Easy Fertility Monitor. Princeton, NJ: Unipath Diagnostics, Company, 2001.

${ }^{20}$ Guida M, Tommaselli GA, Palomba S, Pellicano M, Moccia G, Di Carlo C, Nappi C. Efficacy of methods for determining ovulation in a natural family planning program. Fertil Steril. 1999;72:900-904.

${ }^{21}$ Behre HM, Kuhlage J, Gabner C, Sonntag B, Schem C, Schneider HPG, Nieschlag $\mathrm{E}$. Prediction of ovulation by urinary hormone measurements with the home use ClearPlan Fertility Monitor: Comparison with transvaginal ultrasound scans and serum hormone measurements. Hum Reprod. 2000;15:2478-2482.

Journal of Midwifery \& Women's Health, Vol 59, No. 5 (September/October 2014): pg. 528-532. DOI. This article is (c) Wiley and permission has been granted for this version to appear in e-Publications@Marquette. Wiley does not grant permission for this article to be further copied/distributed or hosted elsewhere without the express permission from Wiley. 
NOT THE PUBLISHED VERSION; this is the author's final, peer-reviewed manuscript. The published version may be accessed by following the link in the citation at the bottom of the page.

${ }^{22}$ Tanabe K, Susumu N, Nishii K. et al. Prediction of the potentially fertile period by urinary hormone measurements using a new home-use monitor: Comparison with laboratory hormone analyses. Hum Reprod. 2001;16(8):1619-1624.

${ }^{23}$ Columbo, B. Evaluation of fertility predictors and comparison of different rules. Genus. 1998;54:153-167.

${ }^{24}$ Arévalo $M$, Jennings $V$, Sinai I. Efficacy of a new method of family planning: The Standard Days Method. Contraception. 2002;65:333-338.

${ }^{25}$ Sinai I, Arévalo M. It's all in the timing: Coital frequency and fertility awareness-based methods of family planning. J Biosoc Sci. 2006 Nov;38(6):763-77.

${ }^{26}$ Nassaralla CL, Stanford JB, Daly KD, Schneider M, Schliep KC, Fehring RJ. Characteristics of the menstrual cycle after discontinuation of oral contraceptives. J Womens Health (Larchmt). 2011;20(2):169-177. 